\title{
Effects of inhaled histamine, methacholine and capsaicin on sputum levels of $\alpha_{2}$-macroglobulin
}

Halla Halldorsdottir, Lennart Greiff, Per Wollmer, Morgan Andersson, Christer Svensson, Ulf Alkner, Carl G A Persson

Department of Clinical Physiology, University Hospital, Malmö, Sweden

$\mathrm{H}$ Halldorsdottir

P Wollmer

Department of Otorhinolaryngology,

Head and Neck

Surgery

L Greiff

M Andersson

C Svensson

Department of Clinical Pharmacology C G A Persson

University Hospital, S-221 85 Lund, Sweden

Department of Bioanalytical Chemistry, Astra Draco, Lund, Sweden U Alkner

Correspondence to: Dr L Greiff.

Received 5 December 1996 Returned to authors

4 February 1997

Revised version received

24 March 1997

Accepted for publication

25 July 1997

\section{Abstract}

Background - Plasma exudation-derived proteins and peptides contribute significantly to inflammation in the airway mucosa in vivo. In the guinea pig trachea both histamine and the neurogenic stimulant capsaicin produce acute mucosal tissue distribution and luminal entry of bulk plasma, whereas cholinergic agonists fail to produce this effect. Of these agents, only histamine induces mucosal exudation of plasma in human nasal airways. The exudative effect of the above agents on human bronchi remains unknown.

Methods - The bronchial exudative responses to inhalation of histamine, methacholine, and capsaicin were examined in two groups of healthy volunteers. Sputum was induced on three occasions in each study group by inhalation of hypertonic saline (4.5\%) given as an aerosol for 40 minutes using an ultrasonic nebuliser. The second and third occasions were preceded by histamine and capsaicin challenges in the first study group, and by histamine and methacholine challenges in the second study group. Histamine and methacholine were given in cumulative doses (total doses $3160 \mu \mathrm{g}$, respectively) or until a $20 \%$ reduction in forced expiratory volume in one second $\left(F_{E V}\right)$ was achieved. Cumulative doses of capsaicin were inhaled until coughing prevented the subjects from drawing a full breath. Sputum levels of $\alpha_{2}$ macroglobulin ( $720 \mathrm{kDa})$ were measured as an index of mucosal exudation of bulk plasma.

Results - Histamine increased mean (SE) sputum levels of $\alpha_{2}$-macroglobulin from $2.72(1.01) \mu \mathrm{g} / \mathrm{ml}$ (95\% confidence interval (CI) 0.49 to 4.94$)$ to $18.38(8.03) \mu \mathrm{g} / \mathrm{ml}(95 \%$ CI 0.49 to 36.27 ) in the first group, and from $1.66(0.84) \mu \mathrm{g} / \mathrm{ml}(95 \%$ CI -0.18 to $3.49)$ to $9.43(3.63) \mu \mathrm{g} / \mathrm{ml}(95 \%$ CI 1.59 to 17.27) in the second group. In contrast, capsaicin evoked no exudation (sputum levels of $\alpha_{2}$-macroglobulin $1.21(0.28) \mu \mathrm{g} /$ $\mathrm{ml}(95 \% \mathrm{CI} 0.59$ to 1.83$))$ and methacholine produced a minor increase in sputum levels of $\alpha_{2}$-macroglobulin (2.90 (0.92) $\mu \mathrm{g} /$ $\mathrm{ml}(95 \%$ CI 0.90 to 4.89$)$ ).

Conclusions - These results indicate that histamine is a useful agent for studying bronchial exudative responsiveness in man and that exudative effects are only of marginal importance in the cough and bronchoconstriction produced by capsaicin and methacholine.

(Thorax 1997;52:964-968)

Keywords: histamine, methacholine, capsaicin, $\alpha_{2}$ macroglobulin, sputum.

Inhalation of either histamine or methacholine is widely used to assess bronchial hyperresponsiveness. ${ }^{12}$ These two agents contract tracheobronchial smooth muscle and it is largely this pharmacological action that causes airway obstruction. However, other actions are not common to both mediators - for example, histamine, being an inflammatory mediator, is a potent exudative agent in many tissues including animal airways ${ }^{3}$ and human nasal airways ${ }^{4}$ whereas methacholine and analogues are without this action or evoke only marginal increases in mucosal output of plasma proteins in vivo, even at high dosage levels. ${ }^{35}$

Inhaled capsaicin causes cough in animals and man. ${ }^{67}$ In guinea pigs and rats, capsaicin also induces prompt entry of plasma (neurogenic exudative inflammation) into the airway lumen. ${ }^{8}$ Increased microvascular permeability, whether due to capsaicin or histamine, is best determined as luminal entry of bulk plasma; plasma extravasated in response to histamine will thus promptly and effectively be transmitted across the epithelial lining, even in airways with a healthy epithelium that has a normal tight junction as an absorption barrier. ${ }^{9}$ This swift and obligatory epithelial passage of bulk plasma may be important in airway defence reactions because the biologically active peptides and proteins contained in the plasma exudate can neutralise agents already on the mucosal surface before epithelial integrity is lost. ${ }^{10}$ The epithelial passage has practical research consequences; exudative indices contained in readily obtained airway surface liquids may adequately reflect increases in the permeability of the subepithelial microcirculation. ${ }^{9}$ Whereas capsaicin evokes luminal entry of bulk plasma in guinea pig airways, ${ }^{8}$ this response has been difficult to detect in human nasal airways. ${ }^{11-13}$ Indeed, capsaicin given at dose levels which cause pain has not produced any detectable exudative response ${ }^{13}$ even in the allergic nasal airways that exhibit both neurogenic hyperresponsiveness (increased pain to topical capsaicin ${ }^{13}$ ) and microvascular exudative hyperresponsiveness (exaggerated exudative response to topical histamine ${ }^{14}$ ). 
The present study was undertaken because there is little information about exudative responses to inhaled mediators in human bronchi. Moreover, even if topical allergen challenge has indicated that there is a luminal entry of bulk plasma in both human bronchi ${ }^{1516}$ and human nasal passages, ${ }^{1617}$ there is no general acceptance of the concept that exudative properties of mediators will be expressed similarly in human nasal and bronchial mucosae. In this study we have thus tested the hypothesis that histamine is an exudative agent in human bronchi. We have also examined whether methacholine and capsaicin produce plasma exudation responses in the lower human airways. In order to obtain airway surface samples we have employed the technique of sputum induction by inhalation of hypertonic saline. As an index of luminal entry of bulk plasma we have analysed sputum levels of $\alpha_{2}$-macroglobulin which is one of the largest plasma proteins and which previously has been validated as a particularly useful index of plasma exudation responses in human airways. ${ }^{1416}$

\section{Methods}

\section{STUDY DESIGN}

Sputum was induced by inhalation of aerosolised hypertonic saline in two separate studies each performed on three study days. On the first day sputum induction was performed without any pharmacological challenge, on the second day sputum induction was preceded by inhalation of aerosolised histamine, and on the third day by inhalation of aerosolised capsaicin (first study) or methacholine (second study). The sputum concentration of $\alpha_{2}$-macroglobulin was measured as an index of mucosal exudation of bulk plasma. The washout time between the challenges was two weeks. The study was of an open design.

\section{SUBJECTS}

Study 1 comprised 11 healthy subjects (nine men) aged $22-30$ years and study 2 comprised 14 separate healthy subjects (seven men) aged 22-25 years. The subjects had no history of allergy, asthma, or recent nasal and bronchial disease, and no history of recent drug treatment. They all had a baseline forced expiratory volume in one second $\left(\mathrm{FEV}_{1}\right)$ of more than $90 \%$ of the predicted $\mathrm{FEV}_{1}$. The study was approved by the local ethics committee and informed consent was obtained.

\section{ADMINISTRATION OF AEROSOLS}

Bronchial challenges with histamine, capsaicin, and methacholine were carried out using a dosimetric aerosol delivery system based on an air jet nebuliser (Spira Electro 2, Respiratory Care Center, Hämenlinna, Finland). Aerosol delivery was set to commence after inhalation of 0.1 litres and nebulisation then continued for one second. The volume of each inspiration was approximately 1.0 litre and the flow rate was approximately $0.5 \mathrm{l} / \mathrm{s}$. The inhaled dose was varied by changing the concentration of the nebulised solution as well as the number of inhaled breaths. Three concentrations were used for each agent. The maximum number of breaths for one dose was 12 . Hypertonic saline was administered using an ultrasonic nebuliser (Aerosonic, DeVilbiss, Somerset, Pennsylvania, USA) which generates droplets with a mass median diameter of $1-5 \mu \mathrm{m}$ at a minimum nebulisation rate of $0.3 \mathrm{ml} / \mathrm{min}$.

\section{BRONCHIAL HISTAMINE AND METHACHOLINE} CHALLENGES

Before the histamine and methacholine challenge series a baseline $\mathrm{FEV}_{1}$ was recorded that is, the highest $\mathrm{FEV}_{1}$ recorded of three consecutive tests - using an electronic spirometer (Vitalograph-Compact II, Buckingham, UK). Thereafter, the subjects inhaled increasing doses of histamine or methacholine starting with an initial dose of $2 \mu \mathrm{g}$. $\mathrm{FEV}_{1}$ was recorded one and three minutes after each challenge. Challenges were continued until a cumulative dose of $3160 \mu \mathrm{g}$ had been given or until a $20 \%$ decrease in $\mathrm{FEV}_{1}$ from baseline was achieved.

BRONCHIAL CAPSAICIN CHALLENGE

Before the capsaicin challenge series a baseline $\mathrm{FEV}_{1}$ was recorded as described above. Thereafter, the subjects inhaled increasing doses of capsaicin starting with an initial dose of $1.5 \mathrm{ng}$. The number of coughs was monitored and $\mathrm{FEV}_{1}$ was recorded one and three minutes after each challenge. Challenges were continued until a cumulative dose of $2410 \mathrm{ng}$ had been given or until a $20 \%$ decrease in $\mathrm{FEV}_{1}$ from baseline was achieved, or until the subjects were unable to take a full breath due to coughing.

\section{SPUTUM INDUCTION}

Sputum was induced by inhalation of hypertonic saline at control and at about five minutes after the histamine, methacholine, and capsaicin challenge tests. Aerosolised hypertonic saline $(4.5 \%)$ was inhaled at resting ventilation rate for 40 minutes. Thereafter, the subject was instructed to rinse the mouth three times with $20 \mathrm{ml}$ water, to clear the throat, and to cough sputum into a container. The quality of the sample was assessed by its macroscopic appearance on a Petri dish. The sample was put into a tube, without attempting to separate sputum from small amounts of any additional fluid, and frozen $\left(-20^{\circ} \mathrm{C}\right)$ for later analysis of $\alpha_{2}$-macroglobulin.

\section{ANALYSIS OF $\alpha_{2}$-MACROGLOBULIN}

The sputum samples were processed by ultrasonication for 15 minutes and centrifugation at $32000 \mathrm{~g}$ for 15 minutes. This procedure was chosen in favour of mucolytic agents to avoid interference with the $\alpha_{2}$-macroglobulin analysis. The levels of $\alpha_{2}$-macroglobulin were measured using a radioimmunoassay sensitive to $7.8 \mathrm{ng} / \mathrm{ml}$. Rabbit anti-human $\alpha_{2}$-macroglobulin (Dakopatts, Copenhagen, Denmark) 
Table 1 Effects of inhalational histamine, capsaicin, and methacholine challenges on mean (SE) FEV (\%) recorded three minutes after challenge in study groups 1 and 2

\begin{tabular}{|c|c|c|c|c|c|c|c|c|c|c|c|}
\hline \multicolumn{6}{|c|}{ Study group 1} & \multicolumn{6}{|c|}{ Study group 2} \\
\hline $\begin{array}{l}\text { Histamine } \\
(\mu g)\end{array}$ & $\begin{array}{l}F E V_{1} \\
(\%)\end{array}$ & $\begin{array}{l}\text { No. of } \\
\text { subjects }\end{array}$ & $\begin{array}{l}\text { Capsaicin } \\
\text { (ng) }\end{array}$ & $\begin{array}{l}F E V_{1} \\
(\%)\end{array}$ & $\begin{array}{l}\text { No of } \\
\text { subjects }\end{array}$ & $\begin{array}{l}\text { Histamine } \\
(\mu g)\end{array}$ & $\begin{array}{l}F E V_{1} \\
(\%)\end{array}$ & $\begin{array}{l}\text { No of } \\
\text { subjects }\end{array}$ & $\begin{array}{l}\text { Methacholine } \\
(\mu g)\end{array}$ & $\begin{array}{l}F E V_{1} \\
(\%)\end{array}$ & $\begin{array}{l}\text { No of } \\
\text { subjects }\end{array}$ \\
\hline 2 & $96(1)$ & 11 & 1.5 & $99(1)$ & 11 & 2 & $99(1)$ & 14 & 2 & $98(1)$ & 14 \\
\hline 10 & $97(1)$ & 11 & 7.6 & 99 (1) & 11 & 10 & $100(1)$ & 14 & 10 & $98(1)$ & 14 \\
\hline 40 & $98(1)$ & 11 & 31 & $100(1)$ & 11 & 40 & $99(1)$ & 14 & 40 & $97(1)$ & 14 \\
\hline 160 & $95(2)$ & 11 & 122 & 99 (1) & 10 & 160 & 91 (3) & 14 & 160 & $95(2)$ & 14 \\
\hline 460 & $86(3)$ & 11 & 351 & $101(1)$ & 5 & 460 & $77(4)$ & 13 & 460 & $93(2)$ & 13 \\
\hline 1360 & $80(3)$ & 8 & 1037 & 100 (1) & 5 & 1360 & $77(4)$ & 7 & 1360 & $87(2)$ & 13 \\
\hline 3160 & $78(4)$ & 3 & 2410 & $101(2)$ & 4 & 3160 & $83(0)$ & 1 & 3160 & $86(2)$ & 10 \\
\hline
\end{tabular}

was used as anti-serum and standard human serum (Behringwerke Diagnostica, Marburg, Germany) as standard. Human $\alpha_{2}$-macroglobulin (Cappel-Organon Teknika, Turnhout, Belgium) was iodinated using the lactoperoxidase method. Tracer and standard (or sample) were mixed with anti-serum before adding goat anti-rabbit anti-serum (Astra Draco, Lund, Sweden). The bound fraction was measured using a gamma counter (Pharmacia, Uppsala, Sweden). The intra-assay and inter-assay coefficients of variation were 3.8$6.0 \%$ and $3.1-7.2 \%$, respectively.

\section{DATA ANALYSIS}

Differences in sputum levels of $\alpha_{2}$-macroglobulin between control and challenge situations were analysed by Friedman test and, if statistical significance emerged, by Wilcoxon signed rank test. A p value of less than 0.05 was considered significant. Data are presented as mean (SE), with or without $95 \%$ confidence intervals (CI) as appropriate.

\section{Results}

The baseline $\mathrm{FEV}_{1}$ recorded before the challenge and sputum induction series was reproducible in both study groups. The mean intra-individual coefficient of variation was $3.30(0.8) \%$ in the first group and $2.6(0.5) \%$ in the second group. Histamine produced dose dependent reductions in $\mathrm{FEV}_{1}$ in both study groups. A mean final cumulative histamine dose of 1851 (376) $\mu \mathrm{g}$ was required to produce a 23 (2)\% reduction in $\mathrm{FEV}_{1}$ in the first group, and a mean dose of 996 (213) $\mu \mathrm{g}$ was required to produce a 28 (3)\% reduction in $\mathrm{FEV}_{1}$ in the second group (table 1 ). Similarly, in the second group methacholine produced a dose dependent reduction in $\mathrm{FEV}_{1}$ with a mean final cumulative methacholine dose of 2528 (287) $\mu \mathrm{g}$ required to produce a 18.4 (2.6)\% reduction in $\mathrm{FEV}_{1}$ (table 1). In contrast, capsaicin did not significantly affect $\mathrm{FEV}_{1}$ (table 1) but produced dose dependent cough finally so intense that the subjects were unable to take a full breath. A mean final cumulative capsaicin dose of 1029 (340) ng produced this effect. The cumulative numbers of coughs associated with capsaicin challenges were 32 (9).

Sputum was obtained in nine out of 11 baseline inductions in the first study group and in all 14 baseline inductions in the second group. After challenge with histamine, capsaicin, and methacholine sputum was obtained at all inductions. Data points from subjects not producing baseline sputum samples have been excluded from the statistical evaluation, but if included they neither affect the outcome nor the results as presented below. The sputum volume recovered varied somewhat between subjects and between challenges, with recovered volumes after control saline, histamine, and capsaicin of $1.70(0.30) \mathrm{g}, 2.34(0.37) \mathrm{g}$, and $1.65(0.26) \mathrm{g}$, respectively, in the first study group and $1.75(0.19) \mathrm{g}, 3.04(0.50) \mathrm{g}$, and $2.54(0.46) \mathrm{g}$ in the second study group. The sputum recovery was significantly increased after histamine in the second group compared with control saline $(p<0.01)$ but otherwise the recovery was not significantly different in the sputum induction series.

Histamine produced significant mucosal exudation of $\alpha_{2}$-macroglobulin in both the first $(\mathrm{p}<0.05)$ and second study group $(\mathrm{p}<0.01)$ (table 2) with sputum levels of $\alpha_{2}$-macroglobulin increasing from $2.72(1.01) \mu \mathrm{g} / \mathrm{ml}$ (95\% CI 0.49 to 4.94 ) to $18.38(8.03) \mu \mathrm{g} / \mathrm{ml}$ (95\% CI 0.49 to 36.27 ) in the first study group, and from $1.66(0.84) \mu \mathrm{g} / \mathrm{ml}(95 \%$ CI -0.18 to 3.49 ) to $9.43(3.63) \mu \mathrm{g} / \mathrm{ml}(95 \%$ CI 1.59 to 17.27 ) in the second group. In contrast, capsaicin failed to produce mucosal exudation of $\alpha_{2}$-macroglobulin $(1.21(0.28) \mu \mathrm{g} / \mathrm{ml}(95 \%$ CI 0.59 to 1.83 ); table 2). Indeed, the total recovery of $\alpha_{2}$-macroglobulin (concentration of $\alpha_{2}$-macroglobulin multiplied by recovered volume of sputum) was significantly reduced by capsaicin challenge $(p<0.05)$. Methacholine produced a minor but significant increase in the sputum levels of $\alpha_{2}$-macroglobulin (2.90 $(0.92) \mu \mathrm{g} / \mathrm{ml}$ (95\% CI 0.90 to 4.89 ), $\mathrm{p}<0.05$; table 2).

Table 2 Mean (SE) sputum levels of $\alpha_{2}$-macroglobulin $(\mu \mathrm{g} / \mathrm{ml})$ at baseline and after challenge with histamine, capsaicin, and methacholine

\begin{tabular}{lclll}
\hline Study group 1 $(n=11)$ & & & Study group 2 $(n=14)$ & \\
\cline { 1 - 1 } \cline { 5 - 6 } Challenge & $\alpha_{2}$-macroglobulin & & Challenge & $\alpha_{2}$ macroglobulin \\
\hline Control & $2.72(1.01)$ & & Control & $1.66(0.84)$ \\
Histamine & $18.38(8.03)^{*}$ & & Histamine & $9.43(3.63)^{* *}$ \\
Capsaicin & $1.21(0.28)$ & & Methacholine & $2.90(0.92)^{*}$ \\
\hline
\end{tabular}

$* \mathrm{p}<0.05, * * \mathrm{p}<0.01$ difference between control and each challenge.

\section{Discussion}

This study, involving healthy subjects, has shown that histamine, in addition to bronchoconstriction, produces marked bronchial mucosal exudation of plasma ( $\alpha_{2}$-macroglobulin). In contrast, methacholine produces bronchoconstriction but only marginally increases the 
sputum levels of $\alpha_{2}$-macroglobulin. We have further shown that a dose of capsaicin that produces a very pronounced cough response fails to produce bronchial mucosal exudation of plasma. These observations provide some basic pharmacological information on the bronchial effects of airway challenge agents which are commonly employed in health and disease. They may also elucidate mechanisms in the human bronchial mucosa including whether or not neurogenic inflammation occurs in man.

Inhalation of hypertonic saline produces bronchoconstriction in patients with asthma whereas this response is not produced in healthy subjects. ${ }^{18}$ Another effect of inhalation of hypertonic saline in man is the induction of sputum production, particularly in patients with asthma, but also in healthy subjects. Whether this response represents a microvascular exudative effect has not been clarified. We have previously shown that nasal administration of hypertonic saline does not affect the baseline appearance of plasma proteins in nasal mucosal surface liquids, but that hypertonic saline may increase plasma exudation responses produced by histamine. ${ }^{19}$ If translatable to human bronchial airways, this finding suggests that hypertonic saline induced sputum production in combination with inhalation challenges with exudative inflammatory mediators, particularly histamine, may be used as an experimental tool in exploring human airway responses.

In the present study we took great care to rinse the oral, pharyngeal, and hypopharyngeal cavities after challenge and before attempting to cough sputum in order to minimise contamination of saliva. ${ }^{20}$ This procedure increases the likelihood that the recovered $\alpha_{2}$-macroglobulin comes from the bronchial airways. The sputum levels of $\alpha_{2}$-macroglobulin have been expressed as the sample concentration, without any correction for sputum volume, thus reflecting as far as possible the concentration of $\alpha_{2}$-macroglobulin in airway mucosal surface liquids as they are after admixture with the inhaled saline and the additional "secretion" that is induced by deposits of hypertonic saline.

We have shown that inhaled histamine produces bronchial exudation of plasma in man. This exudative response was marked at a dose of histamine that produced about a $20 \%$ reduction in $\mathrm{FEV}_{1}$. We have previously shown, by analysis of plasma proteins in nasal lavage fluids, that the mucosal output of $\alpha_{2}$-macroglobulin induced by histamine challenge can be taken to represent output of all plasma proteins. ${ }^{14}$ It has also been shown previously in animal airways that acute microvascular and epithelial passage of plasma induced by an inflammatory stimulus is a non-sieved process. ${ }^{3}$ It therefore appears likely that the levels of $\alpha_{2}-$ macroglobulin recorded in the present study represent mucosal exudation of bulk plasma. It is evident from previous studies involving the human nose $\mathrm{e}^{21}$ and the guinea pig tracheobronchial airways ${ }^{22}$ that, despite the marked increase in the outward (exudative) permeability of the airway epithelium, the mucosal absorption of luminal solutes in histamine ex- posed airways may be unaffected. Hence, the histamine-induced microvascular and epithelial exudation of plasma in the present study cannot suggest any change in the absorption capacity of the bronchial mucosa.

Histamine may be an important mediator in airway inflammation. Particularly in acute allergic asthma, histamine has been found to contribute to the bronchial obstruction. ${ }^{23}$ It has recently been shown that endobronchial allergen challenge is promptly followed by luminal entry of large plasma proteins including fibrinogen ${ }^{15}$ and $\alpha_{2}$-macroglobulin. ${ }^{16}$ The present data, although obtained in healthy subjects, suggest that histamine may be partly responsible for the biologically active molecular milieu of plasma-derived proteins and peptides in the allergic bronchi.

Capsaicin had no effect on bronchial exudation even when given in a dose that produced a strong cough response in healthy subjects. This indicates a high selectivity in action and supports the use of capsaicin as a specific test agent for the assessment of sensory cough responsiveness in human bronchi. ${ }^{67}$ The present observations with capsaicin also suggest that neurogenic inflammatory exudation may not occur in human bronchi. In view of the previous data on human nasal airways where capsaicin has failed to produce plasma exudation in allergic rhinitis even in the presence of a neurogenic hyperresponsiveness ${ }^{13}$ and a microvascular exudative hyperresponsiveness, ${ }^{14}$ this lack of exudation in the human airway should come as no surprise. Although our data argue strongly against the validity of the neurogenic inflammation hypothesis, we do not question the view that the human airway mucosa may hold tachykinergic sensory nerves and that peptide mediators from these nerves exert important physiological effects. ${ }^{24-26}$

The present results with methacholine inhalation are consistent with observations in the human nasal and the guinea pig tracheobronchial airways where even very high dose challenges with agent merely produce a slight increase in the levels of plasma proteins in the mucosal surface liquids. ${ }^{35}$ The slight (1.7-fold) increase in sputum levels of $\alpha_{2}$-macroglobulin seen after methacholine challenge, although statistically significant, needs to be confirmed since there is currently no known mechanism by which muscarinic agents may increase microvascular permeability. In contrast, methacholine and histamine are known to have about the same potency as constrictors of human bronchial smooth muscle. ${ }^{27}$ The difference between histamine and methacholine in their effects on bronchial plasma exudation would favour the use of the latter agent as a more specific bronchoconstrictor by the inhaled route in man.

In studies using histamine as a topical challenge agent a microvascular exudative hyperreponsiveness has been reported in allergic rhinitis ${ }^{14}$ and common cold. ${ }^{28}$ Hence, it would be of interest to explore bronchial exudative responsiveness in health and disease and the present method (involving histamine or another acute vascular permeability agent) may be 
used for this purpose. The flooding of mucosal tissues with the potent binding proteins of plasma and the movement of this plasma exudate into the airway lumen may affect the fate of inflammatory cell products: Accordingly, in patients with ongoing allergic rhinitis we have found that simple histamine challenges move cell products such as interleukin 6 , which is located in the allergic mucosal tissue, into the airway lumen. ${ }^{29}$ It therefore appears possible to use histamine challenge as an experimental aid to improve the recovery of inflammatory cell products by lavage and sputum induction techniques. It should be of particular interest to examine the effect of histamine on the entry of cytokines into the lumen of the airway since these molecules are tightly bound and are carried by the $\alpha_{2}$-macroglobulin ${ }^{30}$ that was shown to increase several fold in this study.

We conclude that mucosal exudation of plasma can be monitored in human bronchial airways by measurement of $\alpha_{2}$-macroglobulin in induced sputum. The known mechanisms of microvascular and epithelial exudation make it unlikely that a challenge could have produced extravasation of plasma into the lamina propria without incurring an increase in luminal levels of plasma proteins that could be sampled by sputum induction. In agreement with previous observations in guinea pig tracheal and human nasal airways, histamine produces mucosal exudation of bulk plasma in human bronchial airways. In contrast, methacholine had only a slight effect and capsaicin failed completely to produce exudative inflammation in human bronchial airways. The latter observation suggests that the concept of neurogenic inflammation may not translate to human bronchi in vivo. Taken together, the present data suggest that histamine may be a useful exudative challenge agent in human bronchi and support the pharmacological selectivity of methacholine and capsaicin as bronchoconstrictor and cough inducing agents, respectively.

This study was supported by the Swedish Medical Research Council (projects 8308 and 10841), the Vardahl Foundation,
and the Swedish Association against Asthma and Allergy. We and the Swedish Association against Asthma and Allergy. We Glans for expert laboratory assistance.

1 Hargreave FE, Woolcock AJ, eds. Airway responsiveness: measurement and interpretation. Mississauga: Astra Pharmaceuticals Canada, 1985 .

2 Woolcock AJ, Salome CM, Yan K. The shape of the doseresponse curve to histamine in asthmatic and normal subjects. Am Rev Respir Dis 1984;130:71-5.

3 Erjefält I, Persson CGA. Inflammatory passage of plasma macromolecules into airway wall and lumen. Pulm Pharmacol 1989;2:93-102.

4 Svensson C, Baumgarten CR, Pipkorn U, Alkner U, Persson CGA. Reversibility and reproducibility of histamine induced plasma leakage in nasal airways. Thorax 1989;44: 13-18

5 Raphael GD, Druce HM, Baraniuk JN, Kaliner MA. The pathophysiology of rhinitis I. Assessment of the sources of protein in methacholine-induced nasal secretions. $A m$ Rev Respir Dis 1988;138:413-20.

6 Collier JG, Fuller RW. Capsaicin inhalation in man and the effects of sodium cromoglycate. $\mathrm{Br} \mathcal{F}$ Pharmacol $1984 ; \mathbf{8 1}$ : $113-7$.

7 Midgren B, Hansson L, Karlsson J-A, Simonsson BG Persson CGA. Capsaicin-induced cough in man. Am Rev Respir Dis 1992;146:347-51.

8 Persson CGA, Erjefält I, Andersson P. Leakage of macromolecules from guinea-pig tracheobronchial microcirculation. Effects of allergen, leukotrienes, tachykinins, and anti-asthma drugs. Acta Physiol Scand 1986;127:95105 .

9 Persson CGA, Svensson C, Greiff L, Andersson M, Wollmer $\mathrm{P}$, Alkner U, et al. Use of the nose to study the inflammatory response in the respiratory tract. Thorax 1992;47:9931000.

10 Persson CGA, Erjefält I, Alkner U, Baumgarten CR, Greiff $\mathrm{L}$, Gustafsson B, et al. Plasma exudation as a first line L, Gustafsson B, et al. Plasma exudation as a fir

11 Bascom R, Kagey-Sobotka A, Proud D. Effect of intranasal capsaicin on symptoms and mediator release. 7 Pharmacol Exp Ther 1991;259:1323-7.

12 Rajakulasingam K, Polosa R, Lau LC, Church MK, Holgate ST, Howarth PH. Nasal effects of bradykinin and capsaicin: influence on plasma protein leakage and role of sensory nerves. F Appl Physiol 1992;72:1418-24.

13 Greiff L, Svensson C, Andersson M, Persson CGA. Effects of topical capsaicin in seasonal allergic rhinitis. Thorax 1995;50:225-9.

14 Svensson C, Andersson M, Greiff L, Alkner U, Persson CGA. Exudative hyperresponsiveness of the airway microcirculation in seasonal allergic rhinitis. Clin Exp Allergy 1995;25:942-50.

15 Salomonsson P, Grönneberg R, Gilljam H, Andersson O, Billing B, Enander I, et al. Bronchial exudation of bulk plasma at allergen challenge in allergic asthma. Am Rev Respir Dis 1992;146:1535-42.

16 Svensson C, Grönneberg R, Andersson M, Alkner U, Andersson $\mathrm{O}$, Billing $\mathrm{B}$, et al. Allergen challenge-induced exudation of $\alpha_{2}$-macroglobulin across human nasal and bronchial microvascular-epithelial barriers. $f$ Allergy Cli Immunol 1995;96:239-46.

17 Naclerio RM, Meier HL, Kagey-Sobotka A, Adkinson Jr. NF, Meyers DA, Norman PS, et al. Mediator release after nasal airway challenge with allergen. Am Rev Respir Dis 1983;128:597-602.

18 Eschenbacher WL, Boushey HA, Sheppard D. Alteration in osmolarity of inhaled aerosols cause bronchoconstriction and cough, but absence of a permeant anion canstiction and cough, but absence of a permeant anion

19 Greiff L, Persson CGA. Effects of hypertonic saline on mucosa exudation of plasma in human airways. Allergy Clin Immunol News 1994;Suppl 2:76.

20 Pizzichini E, Pizzichini MMM, Efthimiadis A, Evans S, Morris MM, Squillace D, et al. Indices of airway inflammation in induced sputum: reproducibility and validity of cell and fluid-phase measurements. Am $\mathcal{F}$ Respir Crit Care Med 1996;154:308-17.

21 Greiff L, Wollmer P, Pipkorn U, Persson CGA. Absorption of ${ }^{51} \mathrm{Cr}$-EDTA across the human nasal mucosa in the presence of topical histamine. Thorax 1991;146:630-2.

22 Greiff L, Eriefält I, Wollmer P, Pipkorn U, Persson CGA Effects of histamine, ethanol, and a detergent on exudation and absorption across the guinea pig airway mucosa in vivo. Thorax 1991;46:700-5

23 Wood-Baker R, Holgate ST. The comparative actions and adverse effect profile of single doses of $\mathrm{H}_{1}$-receptor antihistamines in the airway and skin of subjects with asthma. f Allergy Clin Immunol 1993;91:1005-14.

24 Barnes PJ. Neural control of human airways in health and disease. Am Rev Respir Dis 1986;134:1289-314

25 Joos GF, Germonpre PR, Pauwels RA. Neurogenic inflammation in human airways: is it important? Thorax 1995; 50:217-9.

26 Spina D. Airway sensory nerves: a burning issue in asthma? Thorax 1996;51:335-7.

27 Finney MJB, Karlsson J-A, Persson CGA. Effects of bronchoconstrictors and bronchodilators on a novel bronchoconstrictors and bronchodilators on a novel
human small airway preparation. Br $¥$ Pharmacol 1985; 85:29-36.

28 Greiff L, Andersson M, Akerlund A, Wollmer P, Svensson $\mathrm{C}$, Alkner U, et al. Microvascular exudative hyper$\mathrm{C}$, Alkner U, et al. Microvascular exudative hypercold. Thorax 1994;49:121-7.

29 Persson CGA, Alkner U, Andersson M, Greiff L, Linden C, Svensson C. Histamine challenge-induced 'lamina propria lavage' and mucosal output of IL-6 in human airways. Eur Respir f 1995;8:125s.

30 James K. Interactions between cytokines and $\alpha_{2}$-macroglobulin. Immunol Today 1990;11:163-6. 